\title{
THE LEVEL OF INDICES OF ION COMPOSITION OF BLOOD IN INFANTS WITH CONGENITAL MALFORMATIONS IN SURGICAL CORRECTION
}

\author{
Oleksey Vlasov ${ }^{l}$ \\ ${ }^{1}$ Municipal Enterprise “Dnipropetrovsk Regional Children's Clinical Hospital” of Dnipropetrovsk Regional Council “, Dnipro, Ukraine \\ vlasovalexey75@gmail.com \\ ORCID: http://orcid.org/0000-0003-1575-9872
}

ARTICLE INFO

Article history:

Received date 14.01.2021

Accepted date 19.02.2021

Published date 28.02.202

Section:

Practical medicine

DOI

$10.21303 / 2313-8416.2021 .001671$

KEYW ORDS

infants

congenital malformations

anesthesia

electrolytes
ABSTRACT

Newborns with severe congenital malformations need radical surgical correction as soon as possible for ensure the quality of life of the infant in the future. Pathological changes associated with the underlying pathology may be accompanied to severe disturbances of homeostasis in the postoperative period.

The aim of the study. To assess the level of ionic composition of plasma in infants with congenital malformations during surgical correction and various types of combined anesthesia. Investigated problem: To prevent electrolyte peri- and postoperative complications, it is obligatory to perform preoperative preparation and stabilization of laboratory parameters, for a child with congenital malformations and to monitor they throughout the operation.

The main scientific results: The electrolyte composition in the examined groups of infants did not show significant differences from age norms. The concentration of potassium was the lowest in group III of the examined in comparison with groups I and II at the stage of preparation for surgery ( $p=0.0041 ; p=0.0102)$, induction of anesthesia $(p=0.0053 ; p=0.0054)$, while children of groups I and II were diagnosed with a tendency to the upper limit of normal serum potassium levels during all observation periods. Elevated sodium levels were diagnosed in group III at all stages of surgical treatment and in group II of infants with congenital malformations at the stage of the most painful and traumatic moment of surgery $(159.94 \pm 4.89-$ II, 139.27 $\pm 3.043-$ III, $p=0.1857$ ).

The area of practical use of the research results: pediatric anesthesiology.

Innovative technological product: laboratory control.

Scope of the innovative technological product: neonatal intensive care unit, surgery.

(C) The Author(s) 2021. This is an open access article under the CC BY license http://creativecommons.org/licenses/by/4.0).

\section{Introduction}

\section{1. The object of research}

The object of research is serum electrolyte levels

\section{2. Problem description}

Determination of ion concentration in the blood continues to be relevant, despite the development of instrumental and the latest biochemical methods of analysis used in clinical diagnosis, including in newborns $[1,2]$. The determination of concentrations of ions, such as sodium, potassium and calcium ions may be even more important to assess the severity of the condition of sick premature infants, in particular with respiratory and gastrointestinal disorders $[1,2]$. In scientific works the values of concentrations of sodium, potassium and calcium ions in the blood of healthy premature infants and newborns with perinatal pathology, etc. are given [1, 3]. In addition, the dynamics of $\mathrm{Na}^{+}, \mathrm{K}^{+}$during 7-8 days after birth and $\mathrm{Ca}^{2+}$ during 1-2 days in all newborns is described and discussed, $[2,3]$. In the literature, data on the ionic composition of blood in infants during surgery are insufficient.

\section{3. Suggested solution to the problem}

It is known that newborns with severe surgical pathology due to congenital malformations usually require radical surgical correction as soon as possible to eliminate damage/abnormalities of organs and systems and ensure the quality of life of the child in the future. Pathological changes 
associated with the underlying pathology may be accompanied and/or lead to severe disturbances of homeostasis in the postoperative period $[2,4,5]$.

To prevent metabolic, water-electrolyte peri- and postoperative complications, it is obligatory to perform preoperative preparation and stabilization of vital signs of a child with congenital malformations (CM). For example, the leading pathophysiological factors of homeostasis disorders in children with congenital intestinal obstruction are hypovolemia and dehydration [6, 7]. Therefore, preoperative preparation is aimed at correcting hypovolemia, water-electrolyte disorders and normalization of acid-base status. In addition, children with CM usually have functional immaturity of organs and systems, limited compensatory capacity of the body under damaging effects (hypoxia, acidosis, endotoxemia, etc.) often there are situations of unpredictability of critical conditions and the difficulty of preventive intensive care [2].

At the same time, in the literature there are no data on the quantitative values of the ionic composition of blood in newborns and infants with CM during surgical correction with different types of anesthesia.

The aim of the work. To assess the level of ionic composition of peripheral blood plasma in children with congenital malformations during surgical correction and various types of combined anesthesia.

\section{Materials and methods}

The retrospective study included 150 newborns and infants with congenital malformations (CM) who received surgical treatment in MI "Dnipropetrovsk Regional Children's Clinical Hospital" (Dnipro city) in 2019. The study did not involve children with urgent surgical pathology, as well as infants in the agonal state.

There were formed 3 groups depending on the type of combined anesthesia during surgical correction of anomalies: I - inhalation (sevoran)+regional anesthesia; II - inhalation (sevoran)+intravenous anesthesia (fentanyl); III - total intravenous anesthesia with 2 drugs: analgesic (fentanyl) and medical sleep on the background of intravenous injection of hypnotics ( $20 \%$ sodium oxybutyrate). Operations were performed: thoracic, urological, abdominal.

The Commission on Medical Ethics at the Dnipropetrovsk Regional Children's Clinical Hospital of the Dnipropetrovsk Regional Council on January 5, 2021 (Protocol 1) noted the compliance of the retrospective study with the requirements of biological and medical ethics and allowed open publication of the considered materials.

Retrospective assessment in the study was conducted in the following stages:

1) before surgery and anesthesia;

2) introduction of a child to general anesthesia;

3) traumatic stage of the operation: the middle of the operation or the most painful stage of surgery;

4) postoperative period (within 1 hour after transporting an infant to the intensive care unit);

5) 24 hours after surgery.

During all stages, electrolytes $\left(\mathrm{Na}^{+}, \mathrm{K}^{+}, \mathrm{Ca}^{2+}\right)$ were studied using an ion-selective ionizer of electrolytes and blood gases "Medica Easy Lyte", USA.

Statistical data processing was performed by means of the application program of the system "Statistica". Because the Newman-Cayles test gives a more accurate estimate of the probability of alpha with more comparisons, two-sided significance tests were used and alpha was set for $p<0.05$. Bonferroni's corrections were used to resolve multiple comparisons.

\section{Research results}

According to the nature of CM, the study involved infants with the pathology presented in Table 1. The most common congenital anomalies were intestinal obstruction (24\%) and abdominal tumors $(21.3 \%)$. All infants required preoperative preparation and stabilization due to the severity of the underlying, concomitant and background pathology.

Congenital diseases in infants who required surgical treatment were distributed as follows: abdominal surgery - 98 (67\%), thoracic - 26 (18\%), urological - 23 (15\%). During surgical interventions for congenital malformations, these types of anesthesia type I, II, III had an equal distribution $-33.3 \%$. 
Table 1

Types of malformations in infants, abs. (\%)

\begin{tabular}{|c|c|c|c|c|c|c|c|c|c|}
\hline $\begin{array}{l}\text { Congenital } \\
\text { malforma- } \\
\text { tions }\end{array}$ & $\begin{array}{c}\text { Esophagus } \\
\text { malforma- } \\
\text { tions }\end{array}$ & $\begin{array}{c}\text { Intestinal } \\
\text { obstruc- } \\
\text { tion }\end{array}$ & $\begin{array}{c}\text { Embry- } \\
\text { onal } \\
\text { hernia }\end{array}$ & $\begin{array}{c}\text { Gastroschi- } \\
\text { sis }\end{array}$ & Tumors & $\begin{array}{l}\text { Intestinal } \\
\text { malforma- } \\
\text { tions }\end{array}$ & $\begin{array}{l}\text { Ano-rectal } \\
\text { malforma- } \\
\text { tions }\end{array}$ & $\begin{array}{c}\text { Malfor- } \\
\text { mations of } \\
\text { lungs }\end{array}$ & Total \\
\hline $\begin{array}{l}\text { Number of } \\
\text { children }\end{array}$ & $14(9.3)$ & $36(24)$ & $7(4,7)$ & $9(6)$ & $32(21.3)$ & $14(9.3)$ & 17 (11.3) & $21(14)$ & $150(100)$ \\
\hline
\end{tabular}

The results presented in Table $\mathbf{2}$ show that in thoracic surgery, type II combined anesthesia was most often used and variant III was used the least. In abdominal surgeries, the first variant of anesthesia support was mostly used, while in urological surgeries, combined type III anesthesia ranked first. Probable differences between types of anesthesia in different surgical interventions for congenital pathologies were not found $(p=0.863)$.

Table 2

Distribution of anesthesia type depending on surgical intervention for congenital pathologies in infants, \%

\begin{tabular}{|c|c|c|c|c|}
\hline \multirow[b]{2}{*}{ Type of surgical interventions } & \multicolumn{4}{|c|}{ Types of anesthesia } \\
\hline & $\begin{array}{c}\mathbf{I} \\
n=\mathbf{5 0}\end{array}$ & $\begin{array}{c}\text { II } \\
n=\mathbf{5 0}\end{array}$ & $\begin{array}{c}\text { III } \\
n=50\end{array}$ & $\chi^{2}$ \\
\hline Thoracic $n=26$ & 18.4 & 20.4 & 14.3 & \\
\hline Abdominal $n=98$ & 69.4 & 63.3 & 67.3 & 1200 \\
\hline Urologic $n=23$ & 12.2 & 16.3 & 18.4 & 1.290 \\
\hline Total & 100.00 & 100.00 & 100.00 & \\
\hline
\end{tabular}

The results of the study of the electrolyte composition $\left(\mathrm{Na}^{+}, \mathrm{K}^{+}, \mathrm{Ca}^{2+}\right)$ of blood plasma in the examined groups of infants are presented in Tables 3-5. The analysis of the obtained data did not reveal significant differences between the indicators from the age norms [3]. However, attention is drawn to several patterns.

The concentration of potassium in blood plasma was the lowest in group III of the examined infants as compared with groups I and II at the stage of preparation for surgery $(p=0.0041$; $p=0.0102)$, induction of anesthesia $(p=0.0053 ; p=0.0054)$, while infants of groups I and II were diagnosed with a tendency to the upper limit of normal serum potassium levels during all observation periods (Table 3).

Table 3

Serum potassium in infants with different types of anesthesia depending on the stages of surgery, $\mathrm{mmol} / \mathrm{l}, M \pm m$

\begin{tabular}{cccc}
\hline \multirow{2}{*}{ Stages of surgery } & \multicolumn{3}{c}{ Groups } \\
\cline { 2 - 4 } & I & II & III \\
\hline Onset & $3.990 .71 \pm^{* *}$ & $3.920 .76 \pm * * *$ & $3.560 .59 \pm$ \\
Induction & $3.890 .56 \pm^{* *}$ & $3.920 .63 \pm * * *$ & $3.680 .49 \pm$ \\
Traumatic & $3.760 .64 \pm$ & $3.910 .55 \pm * * *$ & $3.660 .69 \pm$ \\
After surgery & $3.620 .67 \pm$ & $3.790 .55 \pm$ & $3.900 .61 \pm$
\end{tabular}

Note: $p<0.05, *$ - between I+II groups; ** - P between I+III groups; *** - P between II+III groups

When analyzing the concentration of sodium in the serum of all examined groups, a tendency to hypernatremia was established, which indicates dehydration in newborns and infants, disorder of homeostasis on the background of the main congenital pathology. Elevated electrolyte levels were diagnosed in group III at all stages of surgical treatment, especially in group II of infants with CM at the stage of the most painful and traumatic moment of surgery (159.94 \pm 4.89 - group II, 139.27 \pm 3.043 - group III, $p=0.1857$ ) (Table 4).

As a result of research of concentration of the general calcium in a blood plasma of infants with CM against surgical treatment, pathological deviations of an indicator are not established. 
Table 4

Serum sodium in infants with different types of anesthesia depending on the stages of surgery, mmol/l, $M \pm m$

\begin{tabular}{cccc}
\hline \multirow{2}{*}{ Stages of surgery } & \multicolumn{3}{c}{ Groups } \\
\cline { 2 - 4 } & I & II & III \\
\hline Onset & $136.63 \pm 4.39^{*}$ & $136.925 .66 \pm$ & $138.434 .27 \pm$ \\
Induction & $136.49 \pm 4.44^{*}$ & $137.674 .36 \pm$ & $138.303 .78 \pm$ \\
Traumatic & $137.539 .32 \pm$ & $159.944 .89 \pm$ & $139.273 .043 \pm$ \\
After surgery & $137.685 .10 \pm$ & $137.824 .94 \pm$ & $138.633 .95 \pm$ \\
In 24 hours after surgery & $138.734 .78 \pm$ & $138.374 .27 \pm$ & $139.003 .78 \pm$
\end{tabular}

Note: $-p<0.05, *-P$ between I+III groups

Table 5

Serum calcium in infants with different types of anesthesia depending on the stages of surgery, $\mathrm{mmol} / \mathrm{l}, M \pm m$

\begin{tabular}{cccc} 
Stages of surgery & \multicolumn{1}{c}{ Groups } & III \\
Onset & I & II & $1.06 \pm 0.12$ \\
Induction & $1.08 \pm 0.16$ & $1.16 \pm 0.32^{* * *}$ & $1.07 \pm 0.11$ \\
Traumatic & $1.07 \pm 0.13^{*}$ & $1.17 \pm 0.28^{* * *}$ & $1.06 \pm 0.18$ \\
After surgery & $1.06 \pm 0.16^{*}$ & $1.19 \pm 0.29 * * *$ & $1.11 \pm 0.14$ \\
In 24 hours after surgery & $\mathbf{1 . 0 4} \pm \mathbf{0 . 1 8 *}$ & $\mathbf{1 . 1 7} \pm \mathbf{0 . 3 5 * *}$ & $1.14 \pm 0.19$ \\
Note: $p<0.05, *$ - between I+II groups; $* *-$ P between I+III groups; $* * *+P$ between II+III groups & $1.21 \pm 0.33$
\end{tabular}

\section{Discussion}

The relative decrease in serum potassium in children of group III may indicate its transmineralization to body cells on the background of alkalosis may lead to the formation of hemodynamic and cardiovascular disorders in children and/or the synergism of two anesthetic drugs - sodium oxybutyrate and fentonyl, which potentiates the implementation of side effects in the form of hypokalemia.

Hypokalemia in children affects the resting potential of cardiomyocytes and neurons (increased resting can lead to a complete block of action potentials), renal water excretion (impaired concentration function - polyuria) and enhances ammonogenesis (as a result, metabolic alkalosis) [8].

On the other hand, children of groups I and II were diagnosed with a tendency to the upper limit of normal serum potassium levels during all observation periods, and 24 hours after surgery. It is in children who received combined anesthesia by inhalation+intravenous there was a significant increase in serum potassium $-4.24 \pm 0.96$ (compared with groups I and III, $p<0.05$ ) (Table 3), which indicates reduced urinary renal function, probably due to the antidiuretic action of fentanyl and sevoran, which received children of group II as part of anesthesia.

It is known that the use of inhaled anesthetics is associated with rare cases of elevated potassium levels in plasma, which can occur in arrhythmias, children have been fatal in the postoperative period. As the result of the analysis, it was proved that it is necessary to control laboratory parameters of the ionic composition of blood to assess the quality of the stabilization of the state of children with congenital malformations before surgery, during surgery and in the postoperative period.

Elevated sodium levels were diagnosed in group III children at all stages of the clinical study from the beginning of anesthesia to the postoperative period and 24 hours after surgery. Disorder of sodium is accompanied by hypokalemia, as mentioned above (Tables 3, 4).

In children with congenital malformations at the stage of the most painful and traumatic moment of the operation, sodium deviation from normal reference intervals was noted, respectively - 159.94 \pm 4.89 - group II, 139.27 \pm 3.043 - group III, $p>0.05$ (Table 4).

The significant difference is established in the level of calcium in the serum of children of group II in the direction of increase compared with group III at the initial stage of $1.16 \pm 0.32$ and $1.06 \pm 0.12$, at $p<0.05$; with groups I and II - at the stages of induction of anesthesia and in the middle of the operation $-1.17 \pm 0.28$ and $1.07 \pm 0.13$, at $p=0.0328$ and $1.07 \pm 0.11$, at $p<0.05$; at the stage of maximum traumatic and painful moment $-1.19 \pm 0.29$ against $1.06 \pm 0.16(p<0.05), 1.06 \pm 0.18(p<0.05)$, respectively (Table 5).

Further, after the operation in children of group II there is an increase in blood calcium levels with a significant difference between group I $-1.17 \pm 0.35$ vs. $1.04 \pm 0.18$, at $p<0.05$ (Table 5). Rela- 
tively high levels of calcium in children of group II were diagnosed on the background of increased sodium, potassium, decreased diuresis, which may indicate dehydration with water imbalance on the background of surgery and trauma, perhaps, the side effects of sodium oxybutyrate with fentanyl.

Since the distribution by type of surgery in the groups is the same, and the groups are representative, it is more possible to assume the presence of side effects of anesthetics on children, especially group II, who received inhalation anesthesia in combination with intravenous anesthesia. That in the future will be reflected in the effectiveness of the recovery of children.

Taking into account the obtained data, there are no significant electrolyte disturbances in all groups of infants with different types of combined anesthesia and surgery, which indicates high-quality preoperative preparation of infants with $\mathrm{CM}$ and stabilization of the condition for all vital signs.

The importance of monitoring homeostasis indices in newborns was confirmed in studies of the electrolyte balance and acid-base state in premature infants with respiratory disorders in the early neonatal period [9].

The importance of monitoring the parameters of the ionic composition in the blood of newborns was confirmed in studies of the electrolyte balance and acid-base state in premature infants with respiratory disorders in the early neonatal period [10].

Some restrictions in the performance of a clinical study may be blood sampling without the use of micromethods, in which case there is a risk of anemia in the child.

In the future, it is planned to carry out a correlation comparison of the obtained results with the main indicators of vital functions in children with congenital anomalies during anesthesia support during surgical correction of defects.

\section{Conclusions}

Thus, there are no significant, critical electrolyte disturbances in all groups of children with different types of combined anesthesia and surgery, which indicates high-quality preoperative preparation of children with birth defects and stabilization of the condition in all vital indicators.

There are some pathological changes in sodium (hypernatremia) and tendencies to deviations from normal potassium limits, mostly related to the severity of congenital, concomitant and background pathology in newborns and infants, because 98 children (67\%) required serious surgical treatment and in $69.4 \%$ of cases in group I, $63.3 \%$ - in group II, $67.3 \%$ - in group III - of abdominal surgery.

\section{Conflict of interest}

The authors declare that they have no conflicts of interest.

\section{References}

[1] Chemerys, Yu. O. (2017). Preoperative preparation and postoperative intensive care of infants with surgical pathology. Dnipro, 27.

[2] Znamenskaya, T. K., Antipkin, Yu. G., Aryaev, M. L. et. al.; Znamenskaya, T. K. (Ed.) (2020). Neonatology. Lviv: Magnolia, 1500.

[3] Fox, G., Hoque, N., Watts, T. (2017). Oxford Handbook of Neonatology. Oxford University Press, 553. doi: http://doi.org/10.1093/ med/9780198703952.001.0001

[4] Kamata, M., Cartabuke, R. S., Tobias, J. D. (2015). Perioperative care of infants with pyloric stenosis. Pediatric Anesthesia, 25 (12), 1193-1206. doi: http://doi.org/10.1111/pan.12792

[5] Horbatiuk, O. M. (2011). Current state of surgery of newborns in Ukraine and prospects of its development. Neonatolohiia, khirurhiia ta perynatalna medytsyna, 1, 17-20. Available at: http://nbuv.gov.ua/UJRN/Nkhpm_2011_1_1_5

[6] Bednarczyk, D., Makowska, I., Sasiadek, M. M., Smigiel, R. (2014). Somatic Mosaicism in Esophageal Atresia. American Journal of Gastroenterology, 109 (12), 1954-1956. doi: http://doi.org/10.1038/ajg.2014.346

[7] Ziyaeifard, M., Azarfarin, R., Azarfarin, R. (2014). New aspects of anesthetic management in congenital heart disease "common arterial trunk". Journal of research in medical sciences, 19 (4), 368-374.

[8] Lukianchikov, V. S. (2019). Hypokalemia. Russkii meditsinskii zhurnal, 1 (1), 28-32.

[9] Vorobeva, O. V., Klimenko, T. M., Levchenko, L. A. (2011). Korreliatsionnii analiz elektrolitnogo sostava venoznoi krovi u nedonoshennykh novorozhdennykh s dykhatelnymi narusheniiami v rannem neonatalnom periode. Bukovinskii meditsinskii almanakh, 15 (4), 43-47.

[10] Hartnoll, G., Betremieux, P., Modi, N. (2000). Randomised controlled trial of postnatal sodium supplementation on body composition in 25 to 30 week gestational age infants. Archives of Disease in Childhood - Fetal and Neonatal Edition, 82 (1), F24-F28. doi: http://doi.org/10.1136/fn.82.1.f24 